IZA DP No. 5514

Inequality, Inequity Aversion, and the Provision of Public Goods

Felix Kölle

Dirk Sliwka

Nannan Zhou

February 2011 


\title{
Inequality, Inequity Aversion, and the Provision of Public Goods
}

\author{
Felix Kölle \\ University of Cologne
}

Dirk Sliwka

University of Cologne

and IZA

Nannan Zhou

University of Cologne

\section{Discussion Paper No. 5514 \\ February 2011}

\author{
IZA \\ P.O. Box 7240 \\ 53072 Bonn \\ Germany \\ Phone: +49-228-3894-0 \\ Fax: +49-228-3894-180 \\ E-mail: iza@iza.org
}

\begin{abstract}
Any opinions expressed here are those of the author(s) and not those of IZA. Research published in this series may include views on policy, but the institute itself takes no institutional policy positions.

The Institute for the Study of Labor (IZA) in Bonn is a local and virtual international research center and a place of communication between science, politics and business. IZA is an independent nonprofit organization supported by Deutsche Post Foundation. The center is associated with the University of Bonn and offers a stimulating research environment through its international network, workshops and conferences, data service, project support, research visits and doctoral program. IZA engages in (i) original and internationally competitive research in all fields of labor economics, (ii) development of policy concepts, and (iii) dissemination of research results and concepts to the interested public.
\end{abstract}

IZA Discussion Papers often represent preliminary work and are circulated to encourage discussion. Citation of such a paper should account for its provisional character. A revised version may be available directly from the author. 
IZA Discussion Paper No. 5514

February 2011

\section{ABSTRACT}

\section{Inequality, Inequity Aversion, and the Provision of Public Goods}

We investigate the effects of inequality in wealth on the incentives to contribute to a public good when agents are inequity averse and may differ in ability. We show that equality may lead to a reduction of public good provision below levels generated by purely selfish agents. But introducing inequality motivates more productive agents to exert higher efforts and help the group to coordinate on equilibria with less free-riding. As a result, less able agents may benefit from initially disadvantageous inequality. Moreover, the more inequity averse the agents, the more inequality should be imposed even by an egalitarian social planner.

JEL Classification: H41, D31, D63, J31, M52

Keywords: $\quad$ public goods, inequality, inequity aversion, social welfare, voluntary provision, income distribution, heterogeneity

Corresponding author:

Dirk Sliwka

University of Cologne

Herbert-Lewin-Str. 2

50931 Köln

Germany

E-mail: dirk.sliwka@uni-koeln.de 


\section{Introduction}

There is now a broad number of studies indicating that many people tend to dislike inequity. Formal models of inequity aversion such as those by Fehr and Schmidt (1999) or Bolton and Ockenfels (2000) have been quite successful in explaining patterns of behavior observed in laboratory experiments and in the field. ${ }^{1}$ In this paper we analyze the effect of ex-ante inequality in wealth on the motivation of heterogeneous and inequity averse agents to contribute to a public good. While a straightforward conjecture would be that inequity aversion should lead to the optimality of a more egalitarian wealth distribution, we show that the optimal degree of wealth inequality may actually increase with the importance of inequity aversion in the agents' preferences.

We consider a simple setting in which two agents who are inequity averse simultaneously decide on their contributions to a public good. The joined output is increasing in each agent's contribution but both agents may have different abilities which determine the marginal effect of their contributions. When both agents benefit to the same extent from the public good, equality in initial wealth may then lead to inequity as the more able agent provides higher inputs and, in turn, has higher costs. We show that this inequity is endogenously offset to some degree as the agents adapt their contributions. Treating unequal agents equally may then have detrimental effects for the provision of the public good. But allocating a higher wealth to the more able agent may motivate the latter to increase her contribution. When the wealth differential is aligned to the difference in abilities, there will be multiple equilibria in which the agents attain the same utility even though their initial wealth differs. In these equilibria both agents have an incentive to match

\footnotetext{
${ }^{1}$ For experimental evidence see for example Roth and Kagel (1995), Camerer (2003) and Engelmann and Strobel (2004). Using a more general notion of fairness, field evidence is given by e.g. Blinder and Choi (1990), Agell and Lundborg (1995), Campbell and Kamlani (1997), Bewley (1999) and Carpenter and Seki (2006). For a summary of the empirical evidence on social preferences see for instance Fehr and Schmidt (2002) and Sobel (2005).
} 
their group-members' contribution and, in turn, the free-rider problem can be substantially reduced when the agents coordinate on the Pareto-dominant equilibrium. In particular, for intermediate levels of wealth inequality both agents exert higher efforts relative to the efforts maximizing their material payoffs.

We further analyze the optimal degree of inequality for two simple settings. In the first setting, we analyze the agents' individual preferences for redistribution of a given amount of total initial wealth. Here, we show that the less able agent may even benefit from ex-ante wealth inequality to her disadvantage. The reason is that the increased incentives of the more able agent to contribute to the public good can outweigh the loss in ex-ante wealth. In the second setting, we show that not only a utilitarian but also an egalitarian social planner will choose an unequal wealth distribution favoring the more productive agent. Most strikingly, the stronger the agents' inequity aversion, the larger should be the difference in initial wealth. Moreover, we show that an egalitarian wealth distribution can only be optimal when all agents have the same ability. On the contrary, in the case of heterogeneous agents such a policy always leads to a stronger underprovision of the public good causing welfare losses. Finally, we demonstrate that under the optimal distribution of wealth, total contributions are independent of the group composition, i.e. homogeneous and heterogeneous groups provide the same amount of the public good and identical levels of social welfare are attained.

In the existing public good literature, a well established result is that the private provision of a public good is unaffected by any reallocation of income amongst contributing agents. This result has first been shown by Warr (1983) and later been extended by Bergstrom et al. (1986). However, the latter also shows that an income redistribution which increases inequality by transferring wealth from non-contributing individuals to contributing individuals can have positive welfare effects (see also Itaya et al. (1997)). In a similar vein, Andreoni (1990) argues that public good provision can be en- 
hanced by redistributing wealth from less altruistic to more altruistic people. We add to this literature by showing that redistribution can be beneficial even for the case of symmetric preferences and even if the set of contributors is left unchanged. While the reason for inequality in our model stems from the heterogeneity in the agents' characteristics, the agents' fairness concerns appear to be an important factor influencing the optimal degree of inequality.

In recent years, there also has been a couple of (predominantly experimental) studies investigating the effects of wealth heterogeneity on public good provision. However, empirical results from these studies are not clear-cut. While some papers find that inequality leads to lower contributions (e.g. Ostrom et al. (1994), Van Dijk et al. (2002), Cherry et al. (2005) and Anderson et al. (2008)), other studies report a neutral or even positive effect of wealth inequality (e.g. Chan et al. (1999), Buckley and Croson (2006)). ${ }^{2}$ One reason for the non-conclusive evidence might be that these studies investigated inequality only in the income dimension. Yet, the claim of our study is that there is an interplay of inequality in the income dimension and heterogeneity in the agents' characteristics that affect "psychological" inequity costs which might hamper the cooperation in social dilemmas.

In this regard, our paper also contributes to the literature on the interplay of equity and equality in social exchanges (e.g. Homans (1958), Adams (1965), Konow (2000), Cappelen et al. (2007) or Konow et al. (2009)). Psychological equity theory (Adams (1965)) for instance argues that individuals do not strive to receive equal benefits or make equal contributions as long as the ratio between benefits and contributions is similar. Analogously, we show that if agents are sufficiently heterogenous, i.e. if the difference in abilities (and hence their inputs) is large, equity between agents is only feasible when initial wealth levels are unequal suggesting that (in)equality does not necessarily imply (in)equity and vice versa.

\footnotetext{
${ }^{2}$ Chan et al. (1996) find evidence which in line with the model of Bergstrom et al. (1986) on an aggregate level but not an individual level.
} 
Applied to a team context within firms, our study provides insights on the question whether equal wages are always the best wage policy. While it has often been argued that unequal reward schemes provoke morale problems among co-workers leading to lower performances (e.g. Akerlof and Yellen (1990), Bewley (1999)), some other studies questioned whether equal payment, realized by wage compression, does eliminate all these problems. ${ }^{3}$ Winter (2004), for instance, shows that it might be even optimal to reward identical agents differently as coordination can be improved which has recently be confirmed in an experiment by Goerg et al. (2010). In another experiment, Abeler et al. (2010) find that paying equal wages after an unequal performance may lead to inequity and, in turn, to substantially lower efforts and a decline in efficiency over time. But while these papers argue for inequality in ex-post performance rewards, our paper shows that it may even be optimal to introduce ex-ante inequality in the non-performance contingent wage components. Furthermore, our paper also adds to the literature on behavioral contract theory studying the effects of inequity aversion on incentives. ${ }^{4}$ However, while in most of the studies inequity aversion leads to more equal payment structures, our model shows that inequity aversion may be a reason to introduce ex-ante inequality.

The remainder of this paper is structured as follows. The model is described in Section 2. Section 3 presents the equilibrium analysis. In Section 4 we compare the effort levels chosen by inequity averse and purely selfish agents. Section 5 analyzes preferences for redistribution and examines the effects of distribution policies and group composition on the public good provision and social welfare. Section 6 concludes.

\footnotetext{
${ }^{3}$ See e.g. Lazear (1989) who argues that "... it is far from obvious that pay equality has these effects".

${ }^{4}$ For a theoretical investigation of this topic see for instance Itoh (2004), Grund and Sliwka (2005), Huck and Rey-Biel (2006), Demougin et al. (2006), Fehr et al. (2007),ReyBiel (2008), Dur and Glazer (2008), Mohnen et al. (2008), Kragl and Schmid (2009), Neilson and Stowe (2010), Bartling and Von Siemens (2010) and Englmaier and Wambach (2010).
} 


\section{The Model}

Two agents $i$ and $j$ can both contribute to a public good. An agent's contribution depends on her effort $e_{i}$ and her ability $a_{i}$. Individual effort costs are linear in the exerted effort and equal to $c \cdot e_{i}, c \in \mathbb{R}^{+}$. The group output is determined by the sum of both agents' contribution:

$$
a_{i} \sqrt{e_{i}}+a_{j} \sqrt{e_{j}}
$$

The agents directly benefit from a higher group output. Each agent receives a share $\eta$ of the group output indicating her individual valuation of the public good (marginal per capital return). Furthermore, each agent $i$ is provided with an initial endowment $w_{i} \cdot{ }^{5}$ Let $\Delta w_{i}=w_{i}-w_{j}$ be the difference in initial endowments. Both agents are inequity averse with a Fehr and Schmidt (1999) type utility function. An agent's utility is ${ }^{6}$

$$
U_{i}=w_{i}-c \cdot e_{i}+\eta \cdot\left(a_{i} \sqrt{e_{i}}+a_{j} \sqrt{e_{j}}\right)-v\left(w_{i}-c \cdot e_{i}-w_{j}+c \cdot e_{j}\right)
$$

with

$$
v(\Delta)=\left\{\begin{array}{ccc}
-\alpha \cdot \Delta & \text { if } & \Delta<0 \\
\beta \cdot \Delta & \text { if } & \Delta>0
\end{array}\right.
$$

where $\alpha$ measures the "psychological costs" of disadvantageous inequity and $\beta$ that of advantageous inequity. Following Fehr and Schmidt (1999) we assume that $\alpha \geq \beta \geq 0$. Additionally, we assume that $\beta \leq \frac{1}{2} \cdot{ }^{7}$

\footnotetext{
${ }^{5}$ In a team context, $\eta$ represents e.g. the degree of team identification or the intrinsic benefit of the work output and $w_{i}$ represents the wage.

${ }^{6}$ Hence, we allow that the disutility from inequity $v(\Delta)$ depends on the difference of the agents' net-wealth (rewards minus costs of effort).

${ }^{7}$ Note that $\beta>\frac{1}{2}$ connotes a very strong form of inequity aversion implying that expost, agents would be willing to donate parts of their wealth to less wealthy group members up to the point where wealth levels are completely equalized (compare Rey-Biel (2008)). We discuss implications of this assumption at the end of Section 3.
} 


\section{Equilibrium Analysis}

Each agent $i$ maximizes

$$
\max _{e_{i}} w_{i}+\eta \cdot\left(a_{i} \sqrt{e_{i}}+a_{j} \sqrt{e_{j}}\right)-c \cdot e_{i}-v\left(w_{i}-c \cdot e_{i}-w_{j}+c \cdot e_{j}\right)
$$

The function is continuous but not continuously differentiable as it has a kink at $e_{i}=\frac{\Delta w_{i}}{c}+e_{j}$ where $i$ attains the same utility as $j$. Off the kink, the second derivative with respect to $e_{i}$ is $-\frac{\eta a_{i} \sqrt{e_{i}}}{4 e_{i}^{2}}<0$. As the right-sided derivative at the kink is strictly smaller than the left-sided derivative, the function is strictly concave.

We have to consider two possible equilibrium types depending on whether there is inequity in equilibrium or whether both agents are equally well off. In an inequitable equilibrium one agent $i$ is better off given the chosen effort levels, i.e. $w_{i}-c e_{i}>w_{j}-c e_{j}$. Suppose that such an equilibrium exists. When agent $i$ is better off, the following two conditions must hold in equilibrium

$$
\begin{aligned}
& \frac{\partial U_{i}}{\partial e_{i}}=-c+\frac{\eta a_{i}}{2 \sqrt{e_{i}}}+\beta c=0, \\
& \frac{\partial U_{j}}{\partial e_{j}}=-c+\frac{\eta a_{j}}{2 \sqrt{e_{j}}}-\alpha c=0 .
\end{aligned}
$$

The respective equilibrium efforts are therefore

$$
e_{i}^{*}=\frac{\eta^{2} a_{i}^{2}}{4(1-\beta)^{2} c^{2}} \text { and } e_{j}^{*}=\frac{\eta^{2} a_{j}^{2}}{4(1+\alpha)^{2} c^{2}} .
$$

Such an equilibrium exists if at these effort levels we indeed have that $w_{i}-$ $c e_{i}>w_{j}-c e_{j}$ or

$$
w_{i}-c \cdot\left(\frac{\eta^{2} a_{i}^{2}}{4(1-\beta)^{2} c^{2}}\right)>w_{j}-c \cdot\left(\frac{\eta^{2} a_{j}^{2}}{4(1+\alpha)^{2} c^{2}}\right) .
$$

This directly leads to the following result: 
Proposition 1 If and only if the difference in initial wealth $\Delta w_{i} \equiv w_{i}-w_{j}$ is larger than $\frac{\eta^{2}}{4 c}\left(\frac{a_{i}^{2}}{(1-\beta)^{2}}-\frac{a_{j}^{2}}{(1+\alpha)^{2}}\right)$ an inequitable equilibrium exists in which agent $i$ is strictly better off than agent $j$. Then, the equilibrium effort levels are

$$
e_{i}^{*}=\frac{\eta^{2} a_{i}^{2}}{4(1-\beta)^{2} c^{2}} \text { and } e_{j}^{*}=\frac{\eta^{2} a_{j}^{2}}{4(1+\alpha)^{2} c^{2}} .
$$

Note that both agents adapt their efforts as the contribution of the favored agent $i$ increases in the degree of "compassion" $\beta$ and that of her disadvantaged counterpart $j$ decreases in the degree of "envy" $\alpha$. Still, they here end up a situation which is inequitable ex-post. But as the result shows this is only the case when ex-ante inequality is sufficiently large.

We now have to check whether there are also equitable equilibria in which both agents attain the same payoff. In that case $w_{i}-c e_{i}=w_{j}-c e_{j}$ and both agents choose their effort levels at the kink of the respective utility function. An effort tuple $\left(\bar{e}_{i}^{*}, \bar{e}_{j}^{*}\right)$ can be sustained in such an equitable Nash equilibrium if no agent has an incentive to deviate. As the function is strictly concave, necessary and sufficient conditions for the existence of the equilibrium are that for both agents the left hand side derivative of the utility function must be positive at $\left(\bar{e}_{i}^{*}, \bar{e}_{j}^{*}\right)$, the right hand side derivative negative and $w_{i}-c \bar{e}_{i}^{*}=$ $w_{j}-c \bar{e}_{j}^{*}$. Hence, in an equitable equilibrium, the following five conditions must be met: 


$$
\begin{aligned}
\left.\frac{\partial_{-} U_{i}}{\partial e_{i}}\right|_{e_{i}=\bar{e}_{i}^{*}} & =-c+\frac{\eta a_{i}}{2 \sqrt{e_{i}}}+\beta c \geq 0 \Leftrightarrow \bar{e}_{i}^{*} \leq \frac{\eta^{2} a_{i}^{2}}{4(1-\beta)^{2} c^{2}} \\
\left.\frac{\partial_{+} U_{i}}{\partial e_{i}}\right|_{e_{i}=\bar{e}_{i}^{*}} & =-c+\frac{\eta a_{i}}{2 \sqrt{e_{i}}}-\alpha c \leq 0 \Leftrightarrow \bar{e}_{i}^{*} \geq \frac{\eta^{2} a_{i}^{2}}{4(1+\alpha)^{2} c^{2}} \\
\left.\frac{\partial-U_{j}}{\partial e_{j}}\right|_{e_{j}=\bar{e}_{j}^{*}} & =-c+\frac{\eta a_{j}}{2 \sqrt{\bar{e}_{j}^{*}}}+\beta c \geq 0 \Leftrightarrow \bar{e}_{j}^{*} \leq \frac{\eta^{2} a_{j}^{2}}{4(1-\beta)^{2} c^{2}} \\
\left.\frac{\partial_{+} U_{j}}{\partial e_{j}}\right|_{e_{j}=\bar{e}_{j}^{*}} & =-c+\frac{\eta a_{j}}{2 \sqrt{\bar{e}_{j}^{*}}}-\alpha c \leq 0 \Leftrightarrow \bar{e}_{j}^{*} \geq \frac{\eta^{2} a_{j}^{2}}{4(1+\alpha)^{2} c^{2}} \\
\bar{e}_{j}^{*} & =\bar{e}_{i}^{*}-\frac{\Delta w_{i}}{c}
\end{aligned}
$$

From these conditions the following result can be derived:

Proposition 2 If and only if $\frac{\eta^{2}}{4 c}\left(\frac{a_{i}^{2}}{(1+\alpha)^{2}}-\frac{a_{j}^{2}}{(1-\beta)^{2}}\right) \leq \Delta w_{i} \leq \frac{\eta^{2}}{4 c}\left(\frac{a_{i}^{2}}{(1-\beta)^{2}}-\frac{a_{j}^{2}}{(1+\alpha)^{2}}\right)$ there is a continuum of equitable equilibria with

$$
\max \left\{\frac{\eta^{2} a_{i}^{2}}{4(1+\alpha)^{2} c^{2}} ; \frac{\eta^{2} a_{j}^{2}}{4(1+\alpha)^{2} c^{2}}+\frac{\Delta w_{i}}{c}\right\} \leq \bar{e}_{i}^{*} \leq \min \left\{\frac{\eta^{2} a_{i}^{2}}{4(1-\beta)^{2} c^{2}} ; \frac{\eta^{2} a_{j}^{2}}{4(1-\beta)^{2} c^{2}}+\frac{\Delta w_{i}}{c}\right\}
$$

and $\bar{e}_{j}^{*}=\bar{e}_{i}^{*}-\frac{\Delta w_{i}}{c}$

\section{Proof:}

Inserting the equity condition (6) in conditions (4) and (5), we can conclude that an effort level $\bar{e}_{i}^{*}$ can be sustained if and only if

$$
\max \left\{\frac{\eta^{2} a_{i}^{2}}{4(1+\alpha)^{2} c^{2}} ; \frac{\eta^{2} a_{j}^{2}}{4(1+\alpha)^{2} c^{2}}+\frac{\Delta w_{i}}{c}\right\} \leq \bar{e}_{i}^{*} \leq \min \left\{\frac{\eta^{2} a_{i}^{2}}{4(1-\beta)^{2} c^{2}} ; \frac{\eta^{2} a_{j}^{2}}{4(1-\beta)^{2} c^{2}}+\frac{\Delta w_{i}}{c}\right\}
$$

Note that $\frac{\eta^{2} a_{i}^{2}}{4(1+\alpha)^{2} c^{2}}<\frac{\eta^{2} a_{i}^{2}}{4(1-\beta)^{2} c^{2}}$ and $\frac{\eta^{2} a_{j}^{2}}{4(1+\alpha)^{2} c^{2}}+\frac{\Delta w_{i}}{c}<\frac{\eta^{2} a_{j}^{2}}{4(1-\beta)^{2} c^{2}}+\frac{\Delta w_{i}}{c}$. Hence, the set is non-empty for certain values of $\Delta w_{i}$ if

$$
\frac{\eta^{2} a_{i}^{2}}{4(1-\beta)^{2} c^{2}} \geq \frac{\eta^{2} a_{j}^{2}}{4(1+\alpha)^{2} c^{2}}+\frac{\Delta w_{i}}{c}
$$


and

$$
\frac{\eta^{2} a_{j}^{2}}{4(1-\beta)^{2} c^{2}}+\frac{\Delta w_{i}}{c} \geq \frac{\eta^{2} a_{i}^{2}}{4(1+\alpha)^{2} c^{2}}
$$

which is the case when

$$
\frac{\eta^{2} a_{i}^{2}}{4(1+\alpha)^{2} c}-\frac{\eta^{2} a_{j}^{2}}{4(1-\beta)^{2} c} \leq \Delta w_{i} \leq \frac{\eta^{2} a_{i}^{2}}{4(1-\beta)^{2} c}-\frac{\eta^{2} a_{j}^{2}}{4(1+\alpha)^{2} c} .
$$

This result has several interesting implications. First, note that there are always multiple equitable equilibria. The reason is that inequity averse agents have some interest to adapt their own effort according to the group member's effort in order to avoid the disutility from inequity. This leads to a coordination problem as the reaction functions are upward sloping.

Second, the set of equitable equilibria defined by (7) is the larger, the higher the agents' degree of inequity aversion: The more the agents care for equity, the larger is their willingness to adapt their efforts to reduce inequity which may either be triggered by inequality in initial wealth or the group member's effort level. The lower boundary of the equilibrium set is decreasing in $\alpha$ as more "envious" agents are willing to reduce their efforts to avoid being worse off than their group member. Analogously, the upper boundary is increasing in $\beta$ as more "compassionate" agents are more willing to raise their efforts to reduce a group member's disadvantage. Likewise, the set defined by (8) is also increasing in the agents' inequity aversion implying that the stronger the agents' aversion against inequity, the larger may be the maximal initial wealth inequality the agents are willing to offset by adapting their contributions ending up in an equitable equilibrium.

Third, note that the lower boundary for $\Delta w_{i}$ as defined by condition (8) exceeds zero (or the upper boundary is smaller than zero) when the abilities differ strongly and inequity aversion is not too strong. In these cases, equitable equilibria never exist when $\Delta w_{i}=0$ and, hence, equity cannot be attained when wealth is distributed equally. The reason is that due to the 
higher marginal productivity of effort, the more productive agent will have a higher incentive to exert more effort than her less productive fellow agent and, in turn, bears higher costs. But as both agents equally benefit from the public good the more able agent is worse off when both have the same initial wealth. ${ }^{8}$

Finally, the equilibrium effort levels are always bounded from below by $\frac{\eta^{2} a_{i}^{2}}{4(1+\alpha)^{2} c^{2}}$ or $\frac{\eta^{2} a_{j}^{2}}{4(1+\alpha)^{2} c^{2}}$ respectively. Hence, an agent never chooses an effort level of 0 . Figure 1 shows the sustainable equilibrium effort levels of both agents $i$ and $j$ as a correspondence of $\Delta w_{i} \cdot{ }^{9}$ There are two cut-off values for $\Delta w_{i}$. For small values of $\Delta w_{i}\left(=-\Delta w_{j}\right)$ below $\frac{\eta^{2}}{4 c}\left(\frac{a_{i}^{2}}{(1+\alpha)^{2}}-\frac{a_{j}^{2}}{(1-\beta)^{2}}\right)$ there is a unique inequitable equilibrium with $e_{i}^{*}=\frac{\eta^{2} a_{i}^{2}}{4(1+\alpha)^{2} c^{2}}$ and $e_{j}^{*}=\frac{\eta^{2} a_{j}^{2}}{4(1-\beta)^{2} c^{2}}$. For large values of $\Delta w_{i}$ above $\frac{\eta^{2}}{4 c}\left(\frac{a_{i}^{2}}{(1-\beta)^{2}}-\frac{a_{j}^{2}}{(1+\alpha)^{2}}\right)$ there is a unique inequitable equilibrium with $e_{i}^{*}=\frac{\eta^{2} a_{i}^{2}}{4(1-\beta)^{2} c^{2}}$ and $e_{j}^{*}=\frac{\eta^{2} a_{j}^{2}}{4(1+\alpha)^{2} c^{2}}$. For intermediate values of $\Delta w_{i}$ equitable equilibria exist.
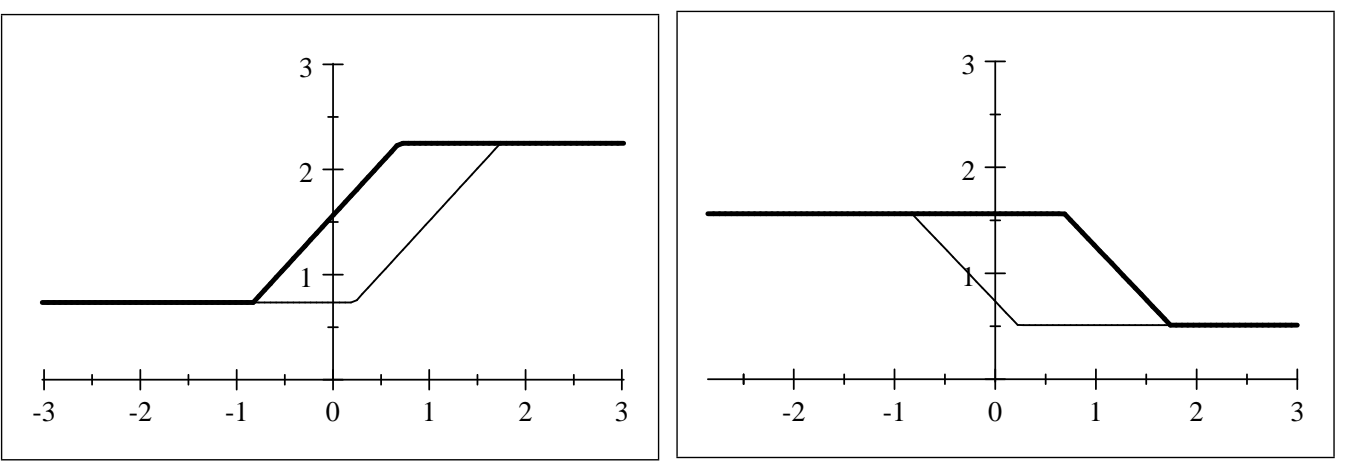

Figure 1: Effort Choice of agent $i$ (left) and $j$ (right) depending on $\Delta w_{i}$

Note that as both agents attain identical payoffs in an equitable equilibrium, they prefer the same one. Consequently, it is important to compare

\footnotetext{
${ }^{8}$ Note that this is always the case when the agents are purely selfish (i.e. $\alpha=\beta=0$ ).

${ }^{9}$ The figure shows a setting in which $a_{i}=12, a_{j}=10, \alpha=0.4, \beta=0.2, \eta=0.2$, and $c=1$.
} 
the different feasible equitable equilibria with respect to the agents' utility which leads to the following result:

Corollary 1 As long as $\beta \leq \frac{1}{2}$ the highest feasible equitable equilibrium is always Pareto optimal.

Proof: See the appendix.

To understand this result note that there is a free-rider problem which is particularly strong when agents are selfish. Inequity aversion helps to overcome this free-rider problem as it allows agents to coordinate on higher effort levels which come closer to the first best. As long as $\beta$ does not exceed $\frac{1}{2}$ the highest feasible equilibrium is still lower than the first-best and therefore is preferred by the agents. With a $\beta$ larger than $\frac{1}{2}$, however, inequity aversion becomes so strong that an agent even would have an incentive to match an inefficiently high effort level chosen by her group member even though both would be better off with a lower effort.

Hence, both agents benefit from playing the equitable equilibrium with the highest sustainable effort level when they are not extremely "compassionate". This effort level is equal to $\min \left\{\frac{\eta^{2} a_{i}^{2}}{4(1-\beta)^{2} c^{2}} ; \frac{\eta^{2} a_{j}^{2}}{4(1-\beta)^{2} c^{2}}+\frac{\Delta w_{i}}{c}\right\}$ and, hence, strictly increasing in the degree of advantageous inequity aversion $\beta$.

\section{Do Inequity Averse Agents Contribute More?}

We now compare the attained effort levels with those chosen by purely selfish agents to study the effects of inequity aversion on the motivation to contribute to the public good. From Propositions 1 and 2 as well as Corollary 1 (assuming that the agents play the Pareto best equitable equilibrium) ${ }^{10}$ we

\footnotetext{
${ }^{10}$ Cooper et al. (1992), Blume and Ortmann (2007) for instance find experimentally that simple ex-ante cheap talk communication indeed very frequently leads to the choice of the pareto efficient Nash equilibrium in coordination games. See Demichelis and Weibull (2008) for a theoretical argument based on lexicographic preferences for honesty.
} 
know that the equilibrium effort levels of inequity averse agents $\left(e_{i}^{*}, e_{j}^{*}\right)$ are given by

$$
\begin{cases}\left(\frac{\eta^{2} a_{i}^{2}}{4(1+\alpha)^{2} c^{2}}, \frac{\eta^{2} a_{j}^{2}}{4(1-\beta)^{2} c^{2}}\right) & \text { if } \Delta w_{i}<\frac{\eta^{2}}{4 c}\left(\frac{a_{i}^{2}}{(1+\alpha)^{2}}-\frac{a_{j}^{2}}{(1-\beta)^{2}}\right) \\ \left(\frac{\eta^{2} a_{j}^{2}}{4(1-\beta)^{2} c^{2}}+\frac{\Delta w_{i}}{c}, \frac{\eta^{2} a_{j}^{2}}{4(1-\beta)^{2} c^{2}}\right) & \text { if } \Delta w_{i} \in\left[\frac{\eta^{2}}{4 c}\left(\frac{a_{i}^{2}}{(1+\alpha)^{2}}-\frac{a_{j}^{2}}{(1-\beta)^{2}}\right), \frac{\eta^{2}}{4 c}\left(\frac{a_{i}^{2}-a_{j}^{2}}{(1-\beta)^{2}}\right)\right] \\ \left(\frac{\eta^{2} a_{i}^{2}}{4(1-\beta)^{2} c^{2}}, \frac{\eta^{2} a_{i}^{2}}{4(1-\beta)^{2} c^{2}}-\frac{\Delta w_{i}}{c}\right) & \text { if } \Delta w_{i} \in\left[\frac{\eta^{2}}{4 c}\left(\frac{a_{i}^{2}-a_{j}^{2}}{(1-\beta)^{2}}\right), \frac{\eta^{2}}{4 c}\left(\frac{a_{i}^{2}}{(1-\beta)^{2}}-\frac{a_{j}^{2}}{(1+\alpha)^{2}}\right)\right] \\ \left(\frac{\eta^{2} a_{i}^{2}}{4(1-\beta)^{2} c^{2}}, \frac{\eta^{2} a_{j}^{2}}{4(1+\alpha)^{2} c^{2}}\right) & \text { if } \Delta w_{i}>\frac{\eta^{2}}{4 c}\left(\frac{a_{i}^{2}}{(1-\beta)^{2}}-\frac{a_{j}^{2}}{(1+\alpha)^{2}}\right)\end{cases}
$$

as depicted by the solid upper boundary of the graphs in Figure 1. Note that both functions are continuous and weakly monotonic.

Suppose, w.l.o.g., that $i$ is the more able agent i.e. $a_{i} \geq a_{j}$. Purely selfish agents' effort choices are not affected by initial wealth inequality as they consider only their marginal returns when choosing their efforts. Hence, efforts are given by ${ }^{11}$

$$
e_{i}^{\text {selfish }}=\frac{\eta^{2} a_{i}^{2}}{4 c^{2}} \text { and } e_{j}^{\text {selfish }}=\frac{\eta^{2} a_{j}^{2}}{4 c^{2}}
$$

By comparing these effort levels of selfish agents with those of inequity averse agents as given by (9) we obtain the following result:

Proposition 3 If $\Delta w_{i} \in\left(\frac{\eta^{2} a_{i}^{2}}{4 c}-\frac{\eta^{2} a_{j}^{2}}{4(1-\beta)^{2} c}, \frac{\eta^{2} a_{i}^{2}}{4(1-\beta)^{2} c}-\frac{\eta^{2} a_{j}^{2}}{4 c}\right)$ both agents contribute more when they are inequity averse (i.e. $e_{i}^{*}>e_{i}^{\text {selfish }}$ and $e_{j}^{*}>$ $\left.e_{j}^{\text {selfish }}\right)$. If $\Delta w_{i}$ is larger than the upper boundary of this set inequity aversion motivates agent $i$ to exert higher efforts but de-motivates agent $j$ (i.e. $e_{i}^{*}>e_{i}^{\text {selfish }}$ and $\left.e_{j}^{*}<e_{j}^{\text {selfish }}\right)$. The opposite holds when $\Delta w_{i}$ is smaller than the lower boundary.

Proof: By comparing (9) with (10) it is straightforward to see that $e_{i}^{*}>$ $e_{i}^{\text {selfish }}$ if $\Delta w_{i} \geq \frac{\eta^{2}}{4 c}\left(\frac{a_{i}^{2}-a_{j}^{2}}{(1-\beta)^{2}}\right)$ and $e_{i}^{*}<e_{i}^{\text {selfish }}$ if $\Delta w_{i} \leq \frac{\eta^{2}}{4 c}\left(\frac{a_{i}^{2}}{(1+\alpha)^{2}}-\frac{a_{j}^{2}}{(1-\beta)^{2}}\right)$.

\footnotetext{
${ }^{11}$ To see that, just replace $\alpha=\beta=0$ in the equilibrium efforts given by (2).
} 
We only have to check the case in which $\Delta w_{i} \in\left(\frac{\eta^{2}}{4 c}\left(\frac{a_{i}^{2}}{(1+\alpha)^{2}}-\frac{a_{j}^{2}}{(1-\beta)^{2}}\right), \frac{\eta^{2}}{4 c}\left(\frac{a_{i}^{2}-a_{j}^{2}}{(1-\beta)^{2}}\right)\right)$. In this case $e_{i}^{*}>e_{i}^{\text {selfish }}$ if

$$
\frac{\eta^{2} a_{j}^{2}}{4(1-\beta)^{2} c^{2}}+\frac{\Delta w_{i}}{c}>\frac{\eta^{2} a_{i}^{2}}{4 c^{2}} \Leftrightarrow \Delta w_{i}>\frac{\eta^{2} a_{i}^{2}}{4 c}-\frac{\eta^{2} a_{j}^{2}}{4(1-\beta)^{2} c} .
$$

Hence, we can conclude that $e_{i}^{*}>e_{i}^{\text {selfish }}$ if $\Delta w_{i}$ exceeds this cutoff. ${ }^{12}$ Analogously, $e_{j}^{*}>e_{j}^{\text {selfish }}$ if $\Delta w_{j}=-\Delta w_{i}>\frac{\eta^{2} a_{j}^{2}}{4 c}-\frac{\eta^{2} a_{i}^{2}}{4(1-\beta)^{2} c}$ which gives us the upper boundary. It is straightforward to check that the interval in which both $e_{i}^{*}>e_{i}^{\text {selfish }}$ and $e_{j}^{*}>e_{j}^{\text {selfish }}$ is non-empty

Hence, the initial wealth differential $\Delta w_{i}$ is crucial to determine how inequity averse agents distort their effort choices relative to the efforts maximizing their material payoffs. For intermediate levels of initial wealth inequality, inequity aversion indeed helps to reduce the free-rider problem as both agents contribute more when coordinating on the Pareto-superior equilibrium.

But if initial wealth inequality becomes stronger, inequity aversion leads to an asymmetric reaction as the favored agent chooses a higher effort than the level maximizing her material payoff and the disadvantaged contributes less than would be optimal from a payoff maximizing perspective.

But it is important to note that the latter demotivating effect may arise for the more able agent even when she is richer than her less able colleague: The lower boundary for $\Delta w_{i}$ in Proposition 3 is larger than zero if

$$
\frac{\eta^{2} a_{i}^{2}}{4 c}-\frac{\eta^{2} a_{j}^{2}}{4(1-\beta)^{2} c}>0 \Leftrightarrow a_{i}>\frac{a_{j}}{1-\beta}
$$

Hence, when $a_{i}$ is much larger than $a_{j}$ or when $\beta$ is sufficiently small, the more able agent reduces her effort below $e_{i}^{\text {selfish }}$ unless $\Delta w_{i}$ exceeds a strictly positive cut-off value. Or, in other words, she has to be paid sufficiently more than her colleague or otherwise will reduce her effort below the selfishly optimal level. To understand the reason for this effect, note again that the payoff

\footnotetext{
${ }^{12}$ Note that this cut-off is indeed always in the interior of the relevant interval.
} 
maximizing effort is always larger for the more able agent as her marginal returns to effort are higher. As both equally benefit from the public good, she is worse off than her less able colleague when both have the same initial wealth. But when being inequity averse she suffers from this disadvantage which is the higher the larger $a_{i}$ relative to $a_{j}$. If $\beta$ is high, the more able agent will still choose an equilibrium effort level above $e_{i}^{\text {selfish }}$ as also her less able but "compassionate" counterpart puts in a sufficiently high effort and they can coordinate to a superior equilibrium. But when $\beta$ is small, she can only reduce inequity by lowering her effort. Hence, not awarding the more able agent more money up front leads to an unfair distribution of payoffs and, in turn, to lower efforts.

\section{Social Welfare, Redistribution, and Group Composition}

We proceed by analyzing redistribution preferences of a) the agents and b) a social planner who can allocate a fixed budget. We further investigate the welfare consequences of a policy implementing an egalitarian wealth distribution irrespective of the distribution of the agents' abilities. Finally, we examine the effect of group composition under the optimal distribution of the initial wealth.

\subsection{Individual Preferences for Redistribution}

We first study the agents' ex-ante preferences on the initial wealth differential $\Delta w_{i}$ when they take into account their equilibrium effort choices. These considerations will be a useful starting point for welfare analysis. To do that, it is instructive to consider a situation in which a certain budget $W=w_{i}+w_{j}$ can be distributed between the two agents. By inserting the equilibrium effort choices (9) into the agents' utility functions we can describe their utility as 
a function of the initial wealth differential $\Delta w_{i}$. Analyzing the shape of the indirect utility functions we obtain the following result:

Proposition 4 The agents' utility function is continuous in $\Delta w_{i}$. If $\Delta w_{i}<$ $\frac{\eta^{2}}{4 c}\left(\frac{a_{i}^{2}-a_{j}^{2}}{(1-\beta)^{2}}\right)$ or $\Delta w_{i}>\frac{\eta^{2}}{4 c}\left(\frac{a_{i}^{2}}{(1-\beta)^{2}}-\frac{a_{j}^{2}}{(1+\alpha)^{2}}\right)$ an agent $i$ 's utility is strictly increasing in $\Delta w_{i}$. But between these two cut-off values it is strictly decreasing. Both agents' utility functions attain a local maximum at $\Delta w_{i}^{*}=\frac{\eta^{2}}{4 c}\left(\frac{a_{i}^{2}-a_{j}^{2}}{(1-\beta)^{2}}\right)$.

Proof: See the appendix.

This result is illustrated in Figure 2. The solid line shows agent $i$ 's utility and the dashed line agent $j$ 's utility both as a function of $\Delta w_{i}{ }^{13}$ For extreme values of $\Delta w_{i}$ each agent benefits from a redistribution in her favor and there is a straightforward conflict of interest between both agents. But in the interval between $\frac{\eta^{2}}{4 c}\left(\frac{a_{j}^{2}}{(1-\beta)^{2}}-\frac{a_{i}^{2}}{(1+\alpha)^{2}}\right)$ and $\frac{\eta^{2}}{4 c}\left(\frac{a_{i}^{2}}{(1-\beta)^{2}}-\frac{a_{j}^{2}}{(1+\alpha)^{2}}\right)$ both agents' interests are fully aligned. The reason is that within this interval only equitable equilibria exist, and hence, any ex-ante inequality in wealth will be offset by adapted effort levels. Moreover, all values of $\Delta w_{i}$ within this interval are Pareto-dominated by a initial wealth differential of $\Delta w_{i}^{*}=\frac{\eta^{2}}{4 c}\left(\frac{a_{i}^{2}-a_{j}^{2}}{(1-\beta)^{2}}\right)$ as at this point, agents can coordinate on an equilibrium leading to the highest contributions.

Proposition 4 has several interesting implications. Consider the situation of an individual agent who can (re-)distribute a given wealth allocation. Interestingly, an individual may benefit from ex-ante redistribution at her own expense as the following result shows:

Corollary 2 If both agents receive the same initial wealth (i.e. $\Delta w_{i}=0$ ) the less able agent $j$ can be made better off by reducing her own initial wealth

\footnotetext{
${ }^{13}$ The figure shows a setting in which $a_{i}=12, a_{j}=10, \alpha=0.4, \beta=0.2, \eta=0.2$, and $c=1$.
} 


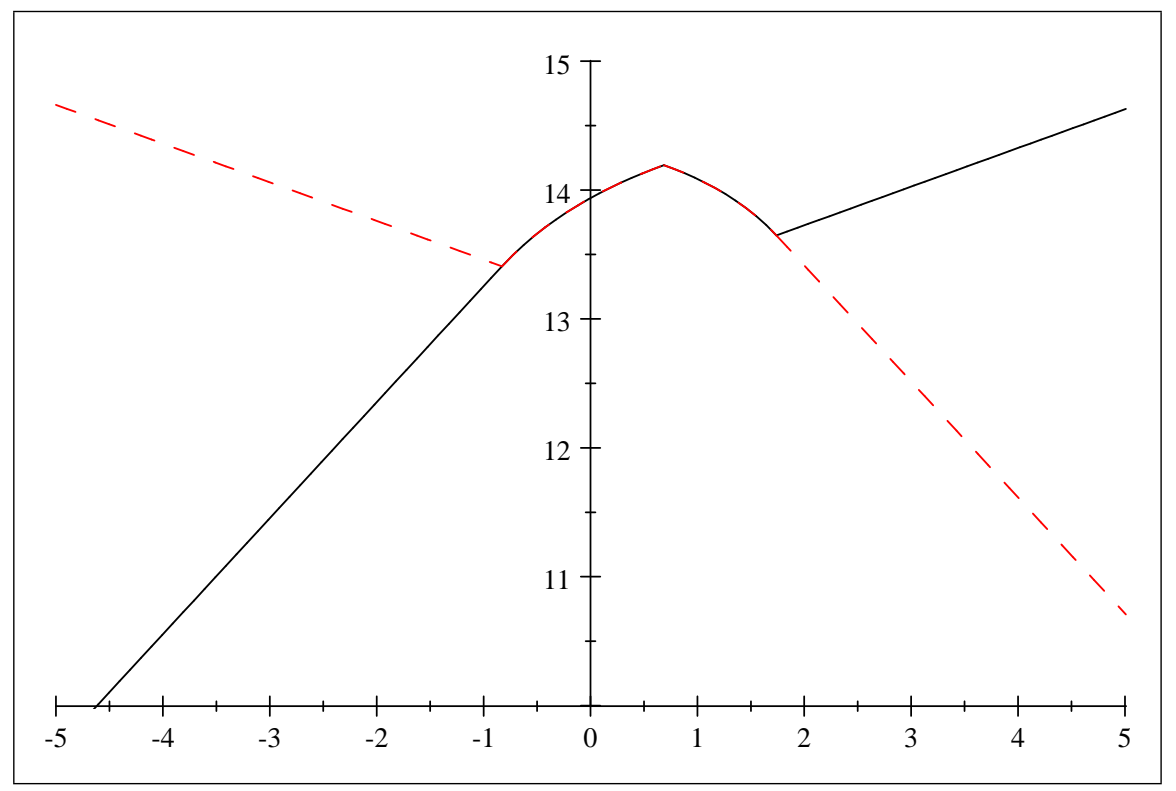

Figure 2: Agent i's and agent j's utilities in equilibrium depending on $\Delta w_{i}$ by $\frac{\eta^{2}}{8 c}\left(\frac{a_{i}^{2}-a_{j}^{2}}{(1-\beta)^{2}}\right)$ and transferring this money to the more able colleague $i$ if

$$
\alpha>\frac{1-\beta}{3-4 \beta} \sqrt{\left(2\left(6 \beta^{2}-7 \beta+2\right)\right)}+\frac{2(1-\beta)^{2}}{(3-4 \beta)}-1
$$

If $\alpha$ is smaller than this cut-off, such a transfer is still beneficial for agent $j$ when her ability is not to small, i.e. if

$$
\frac{a_{j}}{a_{i}}>\min \left\{\frac{1-\beta}{1+\alpha}, \sqrt{\frac{1}{(1-2 \beta)}\left(\frac{4(1-\beta)^{2}}{(1+\alpha)}+1-4(1-\beta)-\frac{2 \beta(1-\beta)^{2}}{(1+\alpha)^{2}}\right)}\right\} .
$$

Proof: See the appendix.

Hence, a less able agent can be better off ex-post when sacrificing parts of her initial wealth which are then transferred to a more able individual. She then benefits from this colleague's higher willingness to contribute to the public good and this helps to reduce the free-rider problem. Interestingly, this 
is always the case irrespective of the difference in abilities if $\alpha$ is sufficiently large. Moreover, note that the cut-off value for $\alpha$ is equal to $\frac{1}{3}$ when $\beta=0$ and strictly decreasing in $\beta$. Hence, this condition holds for moderate values of $\alpha$ even when the agents only suffer from disadvantageous inequity. The reason is that a more able agent resents being worse off than her less able colleague when exerting a higher effort due to her higher productivity. But she is willing to exert higher efforts when she earns more. Therefore, a less able agent may benefit when her colleague's income is increased because, in turn, this colleague is willing to contribute more.

If $\alpha$ is rather small, the result still holds if the less able agent's productivity is not too small relative to her more able colleague's productivity. If, however, her ability is much smaller the transfer necessary to implement a performance maximizing equitable equilibrium is too large such that agent $j$ prefers to stick with the case in which both receive the same initial wealth although this leads to a lower group output.

\subsection{Social Welfare}

We now study a situation in which an external authority can decide on the distribution of wealth. To do so, we consider, a social planner who has a social welfare function which is either egalitarian (i.e. who wants to maximize the utility of the least well-off) or utilitarian (i.e. wants to maximize the sum of both agents' utility). It directly follows from Proposition 4 that such a social planner always has a dominant choice:

Corollary 3 A social planner who is either utilitarian or egalitarian will set $\Delta w_{i}^{*}=\frac{\eta^{2}}{4 c}\left(\frac{a_{i}^{2}-a_{j}^{2}}{(1-\beta)^{2}}\right)$.

Proof: It is straightforward to see that within the set of initial wealth differentials inducing equitable equilibria both egalitarian and utilitarian planners will always choose $\Delta w_{i}^{*}=\frac{\eta^{2}}{4 c}\left(\frac{a_{i}^{2}-a_{j}^{2}}{(1-\beta)^{2}}\right)$ as at this spread, both the sum and the 
minimum of the agents' utilities are maximized. Moreover, for an egalitarian social planner any wealth differential which is not inducing an equitable equilibrium is always dominated by this choice as the utility of the least well off agent is always lower in an inequitable equilibrium. To see this formally note that when, w.l.o.g., $j$ is favored $\frac{\partial u_{i}}{\partial \Delta w_{i}}=\frac{1}{2}+\alpha>0$ for all $\Delta w_{i}$ inducing an inequitable equilibrium (see (12) in the proof of Proposition 4) and as the utility function is continuous, $i$ 's utility is always larger in an equitable equilibrium.

A utilitarian social planner will neither choose a wealth distribution inducing an inequitable equilibrium, as in an inequitable equilibrium which, w.l.o.g., favors agent $j$, the marginal gain from transferring money to agent $i$ $\frac{\partial u_{i}}{\partial \Delta w_{i}}=\frac{1}{2}+\alpha$ is always larger than $j$ 's marginal loss which is equal to $\frac{1}{2}-\beta$ (see again (12)).

Hence, even an egalitarian social planner who only considers the utility of the least well off individual should allow for inequality in ex-ante wealth. The reason is that it is precisely this ex-ante inequality induces an equilibrium in which equity is attained ex-post and in which the more able agent is willing to contribute more. This observation bears some resemblance to the result by Andreoni (1990) who argues that redistribution of income will increase the total contribution if it benefits the more altruistic individuals. ${ }^{14}$ It directly follows that the implementation of an egalitarian wealth distribution policy has detrimental effects if the group considered is not entirely homogenous in terms of abilities.

\subsection{The Optimal Group Composition}

So far, we only considered how wealth should be distributed treating the composition of agents within a group as exogenously given. However, it is

\footnotetext{
${ }^{14}$ Similarly, with respect to social welfare, Thurow (1971) argues that some redistribution of income is necessary in order to achieve a Pareto optimum.
} 
also interesting to study the case in which the formation of groups can be determined as well. A straightforward conjecture is that group composition matters for the willingness to contribute if the agents are inequity averse towards their fellow group members. To investigate this, we consider a simple situation in which there are two agents of high and two of low ability that can be assigned into two groups of two. By comparing total contributions, we can derive the following result:

Proposition 5 If all agents have the same initial wealth, total contributions are always higher with homogenous than with heterogenous groups. But when wealth can be adapted optimally, total contributions are independent of the group composition.

Proof: Let $a_{H}>a_{L}$ be the ability of the high and low productive agent and let $w_{H}$ and $w_{L}$ denote the initial wealth levels of the two agents, respectively. Given the same initial wealth $\left(\Delta w=w_{H}-w_{L}=0\right)$ the total contribution with two homogenous groups is equal to

$$
\frac{2 \eta^{2} a_{H}^{2}}{4(1-\beta)^{2} c^{2}}+\frac{2 \eta^{2} a_{L}^{2}}{4(1-\beta)^{2} c^{2}}=\frac{\eta^{2}\left(a_{H}^{2}+a_{L}^{2}\right)}{2(1-\beta)^{2} c^{2}}
$$

With heterogenous groups it is given by

$$
\begin{array}{ccc}
\frac{\eta^{2} a_{H}^{2}}{2(1+\alpha)^{2} c^{2}}+\frac{\eta^{2} a_{L}^{2}}{2(1-\beta)^{2} c^{2}} & \text { if } & \Delta w<\frac{\eta^{2}}{4 c}\left(\frac{a_{H}^{2}}{(1+\alpha)^{2}}-\frac{a_{L}^{2}}{(1-\beta)^{2}}\right) \\
\frac{\eta^{2}\left(a_{L}^{2}+a_{L}^{2}\right)}{2(1-\beta)^{2} c^{2}} & \text { if } & \Delta w \in\left[\frac{\eta^{2}}{4 c}\left(\frac{a_{H}^{2}}{(1+\alpha)^{2}}-\frac{a_{L}^{2}}{(1-\beta)^{2}}\right), \frac{\eta^{2}}{4 c}\left(\frac{a_{H}^{2}-a_{L}^{2}}{(1-\beta)^{2}}\right)\right]
\end{array}
$$

In both cases, the expression is strictly smaller than (11).

If, however, the distribution of the initial wealth can be optimally adapted, i.e. $\Delta w^{*}=\frac{\eta^{2}}{4 c}\left(\frac{a_{H}^{2}-a_{L}^{2}}{(1-\beta)^{2}}\right)$, the total contribution of two heterogenous groups is

$$
\begin{aligned}
2\left(\frac{\eta^{2} a_{H}^{2}}{4(1-\beta)^{2} c^{2}}+\frac{\eta^{2} a_{H}^{2}}{4(1-\beta)^{2} c^{2}}-\frac{\Delta w^{*}}{c}\right) & =\frac{2 \eta^{2} a_{H}^{2}}{4(1-\beta)^{2} c^{2}}+\frac{2 \eta^{2} a_{H}^{2}}{4(1-\beta)^{2} c^{2}}-\frac{2 \eta^{2}}{4 c^{2}}\left(\frac{a_{H}^{2}-a_{L}^{2}}{(1-\beta)^{2}}\right) \\
& =\frac{2 \eta^{2}\left(a_{H}^{2}+a_{L}^{2}\right)}{4(1-\beta)^{2} c^{2}} .
\end{aligned}
$$


But this is equal to the total contribution of the homogenous groups which is again given by (11) as $\Delta w^{*}=0$ is optimal in this case.

Hence, when the wealth level is fixed and equally distributed it is beneficial to have homogenous groups. The reason is straightforward from the analysis above: Heterogeneity in abilities leads to a de-motivation of the more qualified agent when wealth is equally distributed. By matching agents into homogenous teams, this de-motivational effect can be avoided and group homogeneity helps the agents to coordinate on more favorable equilibria.

It is, however, interesting to note that group composition is irrelevant for total contributions when the wealth level can be optimally adapted. In this case,be the disadvantage of the more able agent can be entirely offset and, in turn, motivation to contribute is restored to the levels attainable in homogenous groups.

\section{Conclusion}

We analyzed the effects of wealth inequality on the incentives to contribute to a public good when agents are inequity averse. We have shown that it is optimal to introduce ex-ante inequality in wealth if agents differ in their abilities. The reason is that inequality in favor of a more able agent can motivate this agent to exert higher efforts. In particular, the stronger the agents' inequity aversion, the stronger is also this incentive effect of inequality and the larger should be the difference in initial wealth. Furthermore, we have shown that compared to the case when agents are purely self-interested, contributions are higher when agents are inequity averse as inequity aversion helps to reduce the free-rider problem and agents can coordinate on higher efforts.

Our results have several interesting implications. First of all, they cast doubt on simple statements sometimes heard in practice claiming that in- 
equality among the members of a group is demotivating when people care for fairness. While this is indeed true for very large wealth differentials in our model, the opposite can also be the case, when wealth differentials are too small. Allocating agents of different abilities the same initial wealth can lead to highly inequitable situations. The reason is that in a public good setting, all agents equally benefit from the group output, but more able agents exert higher efforts as their marginal returns to effort are higher and, in turn, they incur higher costs. When agents are inequity averse this can demotivate the more able agents which is bad for the overall performance as their contributions are more valuable.

The results also may cast some light on the discussion about distributional politics (Alesina and Angeletos (2005), Durante and Putterman (2009)) and the effects on citizens' willingness to voluntary donate to a common good. Some previous studies (e.g. Warr (1983) and Bergstrom et al. (1986)) have argued that the total provision of a public good is independent of the distribution of wealth. In contrast, our results indicate that equality in wealth may crowd-out the motivation to contribute. But introducing inequality may have positive effects on the citizens' willingness to work for the common good. However, our model also shows that this is the case only if the higher wealth is in the hands of those who can provide the most valuable contributions. 


\section{References}

Abeler, J., S. Altmann, S. Kube, and M. Wibral (2010). Gift exchange and workers' fairness concerns: When equality is unfair. Journal of the European Economic Association 8(6), 1299-1324.

Adams, J. (1965). Inequality in social exchange. In L. Berkowitz (Ed.), Advances in Experimental Psychology, pp. 267-299. New York: Academic Press.

Agell, J. and P. Lundborg (1995). Theories of pay and unemployment: Survey evidence from swedish manufacturing firms. Scandinavian Journal of Economics 97(2), 295-307.

Akerlof, G. A. and J. L. Yellen (1990). The fair wage-effort hypothesis and unemployment. The Quarterly Journal of Economics 105(2), 255-283.

Alesina, A. and G.-M. Angeletos (2005). Fairness and redistribution. American Economic Review 95(4), 960-980.

Anderson, L., J. Mellor, and J. Milyo (2008). Inequality and public good provision: An experimental analysis. Journal of Socio-Economics 37(3), 1010-1028.

Andreoni, J. (1990). Impure altruism and donations to public goods: A theory of warm-glow giving. The Economic Journal 100, 464-477.

Bartling, B. and F. Von Siemens (2010). Equal sharing rules in partnerships. Journal of Institutional and Theoretical Economics 166(2), 299-320.

Bergstrom, T. C., L. Blume, and H. Varian (1986). On the private provision of public goods. Journal of Public Economics 29, 25-49.

Bewley, T. (1999). Why Wages Don't Fall During a Recession. Harvard University Press. 
Blinder, A. S. and D. H. Choi (1990). A shred of evidence on theories of wage stickiness. The Quarterly Journal of Economics 105(4), 1003-1015.

Blume, A. and A. Ortmann (2007). The effects of costless pre-play communication: Experimental evidence from games with Pareto-ranked equilibria. Journal of Economic Theory 132(1), 274-290.

Bolton, G. E. and A. Ockenfels (2000). ERC - a theory of equity, reciprocity and competition. American Economic Review 90, 166-193.

Buckley, E. and R. Croson (2006). Income and wealth heterogeneity in the voluntary provision of linear public goods. Journal of Public Economics 90(4-5), 935-955.

Camerer, C. (2003). Behavioral Game Theory: Experiments on Strategic Interaction. Princeton: Princeton University Press.

Campbell, C. and K. Kamlani (1997). The reasons for wage rigidity: Evidence from a survey of firms. The Quarterly Journal of Economics 112, 759-789.

Cappelen, A. W., A. D. Hole, E. O. Sorensen, and B. Tungodden (2007). The pluralism of fairness ideals: An experimental approach. American Economic Review 97(3), 818-827.

Carpenter, J. P. and E. Seki (2006). Competitive work environments and social preferences: Field experimental evidence from a japanese fishing community. The B.E. Journal of Economic Analysis $\&$ Policy 0(2).

Chan, K., S. Mestelman, R. Moir, and R. Muller (1996). The voluntary provision of public goods under varying income distributions. Canadian Journal of Economics 29(1), 54-69.

Chan, K., S. Mestelman, R. Moir, and R. Muller (1999). Heterogeneity and the voluntary provision of public goods. Experimental Economics 2(1), $5-30$. 
Cherry, T., S. Kroll, and J. Shogren (2005). The impact of endowment heterogeneity and origin on public good contributions: evidence from the lab. Journal of Economic Behavior \& Organization 57(3), 357-365.

Cooper, R., D. DeJong, R. Forsythe, and T. Ross (1992). Communication in coordination games. The Quarterly Journal of Economics 107(2), 739771.

Demichelis, S. and J. Weibull (2008). Language, Meaning, and Games: A Model of Communication, Coordination, and Evolution. The American Economic Review 98(4), 1292-1311.

Demougin, D., C. Fluet, and C. Helm (2006). Output and wages with inequality averse agents. Canadian Journal of Economics 39(2), 399-413.

Dur, R. and A. Glazer (2008). Optimal contracts when a worker envies his boss. Journal of Law, Economics, and Organization 24(1), 120-137.

Durante, R. and L. Putterman (2009). Preferences for redistribution and perception of fairness: An experimental study. Working Paper.

Engelmann, D. and M. Strobel (2004). Inequality aversion, efficiency and maximin preferences in simple distribution experiments. American Economic Review 94, 857-869.

Englmaier, F. and A. Wambach (2010). Optimal incentive contracts under inequity aversion. Games and Economic Behavior 69(2), 312-328.

Fehr, E., A. Klein, and K. M. Schmidt (2007). Fairness and contract design. Econometrica 75(1), 121-154.

Fehr, E. and K. M. Schmidt (1999). A theory of fairness, competition, and cooperation. Quarterly Journal of Economics 114, 817-868. 
Fehr, E. and K. M. Schmidt (2002). Theories of fairness and reciprocity - evidence and economic applications. In M. Dewatripont, L. Hansen, and S. Turnovsky (Eds.), Advances in Economics and Econometrics - 8th World Congress.

Goerg, S. J., S. Kube, and R. Zultan (2010). Treating equals unequally - incentives in teams, workers' motivation and production technology. Journal of Labor Economics 28, 747-772.

Grund, C. and D. Sliwka (2005). Envy and compassion in tournaments. Journal of Economics and Management Strategy 14, 187-207.

Homans, G. C. (1958). Social behavior as exchange. The American Journal of Sociology 63(6), 597-606.

Huck, S. and P. Rey-Biel (2006). Endogenous leadership in teams. Journal of Institutional and Theoretical Economics (JITE) 162(2), 253-261.

Itaya, J., D. De Meza, and G. Myles (1997). In praise of inequality: public good provision and income distribution. Economics Letters 57(3), 289296.

Itoh, H. (2004). Moral hazard and other-regarding preferences. The Japanese Economic Review 55(1), 18-45.

Konow, J. (2000). Fair shares: Accountability and cognitive dissonance in allocation decisions. American Economic Review 90(4), 1072-1091.

Konow, J., T. Saijo, and K. Akai (2009). Morals and mores? experimental evidence on equity and equality. Working Paper.

Kragl, J. and J. Schmid (2009). The impact of envy on relational employment contracts. Journal of Economic Behavior \&3 Organization 72(2), 766-779.

Lazear, E. P. (1989). Pay equality and industrial politics. Journal of Political Economy 97, 561-580. 
Mohnen, A., K. Pokorny, and D. Sliwka (2008). Transparency, Inequity Aversion, and the Dynamics of Peer Pressure in Teams: Theory and Evidence. Journal of Labor Economics 26(4), 693-720.

Neilson, W. and J. Stowe (2010). Piece-rate contracts for other-regarding workers. Economic Inquiry 48(3), 575-586.

Ostrom, E., R. Gardner, and J. Walker (1994). Rules, games, and commonpool resources. Univ of Michigan Pr.

Rey-Biel, P. (2008). Inequity aversion and team incentives. Scandinavian Journal of Economics 110(2), 297-320.

Roth, A. and J. Kagel (1995). Bargaining experiments. In Handbook of Experimental Economics. Princeton University Press.

Sobel, J. (2005). Interdependent preferences and reciprocity. Journal of Economic Literature 43, 392-436.

Thurow, L. (1971). The income distribution as a pure public good. The Quarterly Journal of Economics 85(2), 327-336.

Van Dijk, F., J. Sonnemans, and F. Van Winden (2002). Social ties in a public good experiment. Journal of Public Economics 85(2), 275-299.

Warr, P. G. (1983). The private provision of a public good is independent of the distribution of income. Economics Letters 13, 207-211.

Winter, E. (2004). Incentives and discrimination. American Economic Review $94(3), 764-773$. 


\section{Appendix}

\section{Proof of Corollary 1:}

The value of $e_{i}^{\max }$ directly follows from the upper boundary given by (7). Let

$$
v_{i}^{E}\left(e_{i}\right)=w_{i}-c e_{i}+\eta\left(a_{i} \sqrt{e_{i}}+a_{j} \sqrt{e_{i}-\frac{\Delta w_{i}}{c}}\right)
$$

be agent $i$ 's utility which is equal to agent $j$ 's utility in any equitable equilibrium. To compare the equilibria in the set defined by (7) we have to check which value of $e_{i}$ maximizes this utility. Note that

$$
\begin{aligned}
\frac{\partial v_{i}^{E}\left(e_{i}\right)}{\partial e_{i}} & =-c+\eta\left(\frac{a_{i}}{2 \sqrt{e_{i}}}+\frac{a_{j}}{2 \sqrt{e_{i}-\frac{\Delta w_{i}}{c}}}\right) \text { and } \\
\frac{\partial^{2} v_{i}^{E}\left(e_{i}\right)}{\partial e_{i}^{2}} & =\eta\left(-\frac{a_{i}}{4} e_{i}^{-\frac{3}{2}}-\frac{a_{j}}{4}\left(e_{i}-\frac{\Delta w_{i}}{c}\right)^{-\frac{3}{2}}\right)<0 .
\end{aligned}
$$

As $v_{i}^{E}\left(e_{i}\right)$ is strictly concave, $\left.\frac{\partial v_{i}^{E}\left(e_{i}\right)}{\partial e_{i}}\right|_{e_{i}=e_{i}^{\max }} \geq 0$ is a necessary and sufficient condition for $e_{i}^{\max }$ to be Pareto optimal. If $\Delta w_{i}<\frac{\eta^{2}}{4 c}\left(\frac{a_{i}^{2}}{(1-\beta)^{2}}-\frac{a_{j}^{2}}{(1-\beta)^{2}}\right), e_{i}^{\max }$ is equal to $\frac{\eta^{2} a_{j}^{2}}{4(1-\beta)^{2} c^{2}}+\frac{\Delta w_{i}}{c}$ and the condition is equivalent to

$$
\begin{gathered}
-c+\eta\left(a_{i} \frac{1}{2 \sqrt{\frac{\eta^{2} a_{j}^{2}}{4(1-\beta)^{2} c^{2}}+\frac{\Delta w_{i}}{c}}}+a_{j} \frac{1}{2 \sqrt{\frac{\eta^{2} a_{j}^{2}}{4(1-\beta)^{2} c^{2}}+\frac{\Delta w_{i}}{c}-\frac{\Delta w_{i}}{c}}}\right) \geq 0 \Leftrightarrow \\
\Delta w_{i} \leq \frac{\eta^{2}}{4 c}\left(\frac{a_{i}^{2}}{\beta^{2}}-\frac{a_{j}^{2}}{(1-\beta)^{2}}\right) .
\end{gathered}
$$

But $\frac{\eta^{2}}{4 c}\left(\frac{a_{i}^{2}}{\beta^{2}}-\frac{a_{j}^{2}}{(1-\beta)^{2}}\right) \geq \frac{\eta^{2}}{4 c}\left(\frac{a_{i}^{2}}{(1-\beta)^{2}}-\frac{a_{j}^{2}}{(1-\beta)^{2}}\right)$ as long as $\beta \leq \frac{1}{2}$. Hence, both agent's utility is maximal at $e_{i}^{\max }$ in this case. If, however, $\Delta w_{i} \geq$ $\frac{\eta^{2}}{4 c}\left(\frac{a_{i}^{2}}{(1-\beta)^{2}}-\frac{a_{j}^{2}}{(1-\beta)^{2}}\right), e_{i}^{\max }$ is equal to $\frac{\eta^{2} a_{i}^{2}}{4(1-\beta)^{2} c^{2}}$ and the condition is equivalent 
to

$$
\begin{gathered}
-c+\eta\left(a_{i} \frac{1}{2 \sqrt{\frac{\eta^{2} a_{i}^{2}}{4(1-\beta)^{2} c^{2}}}}+a_{j} \frac{1}{2 \sqrt{\frac{\eta^{2} a_{i}^{2}}{4(1-\beta)^{2} c^{2}}-\frac{\Delta w_{i}}{c}}}\right) \geq 0 \Leftrightarrow \\
\Delta w_{i} \geq \frac{\eta^{2}}{4 c}\left(\frac{a_{i}^{2}}{(1-\beta)^{2}}-\frac{a_{j}^{2}}{\beta^{2}}\right)
\end{gathered}
$$

But $\frac{\eta^{2}}{4 c}\left(\frac{a_{i}^{2}}{(1-\beta)^{2}}-\frac{a_{j}^{2}}{\beta^{2}}\right) \leq \frac{\eta^{2}}{4 c}\left(\frac{a_{i}^{2}}{(1-\beta)^{2}}-\frac{a_{j}^{2}}{(1-\beta)^{2}}\right)$ is again equivalent to $\beta \leq \frac{1}{2}$

\section{Proof of Proposition 4:}

By substituting the equilibrium efforts (9) into agent $i$ 's utility function we obtain:

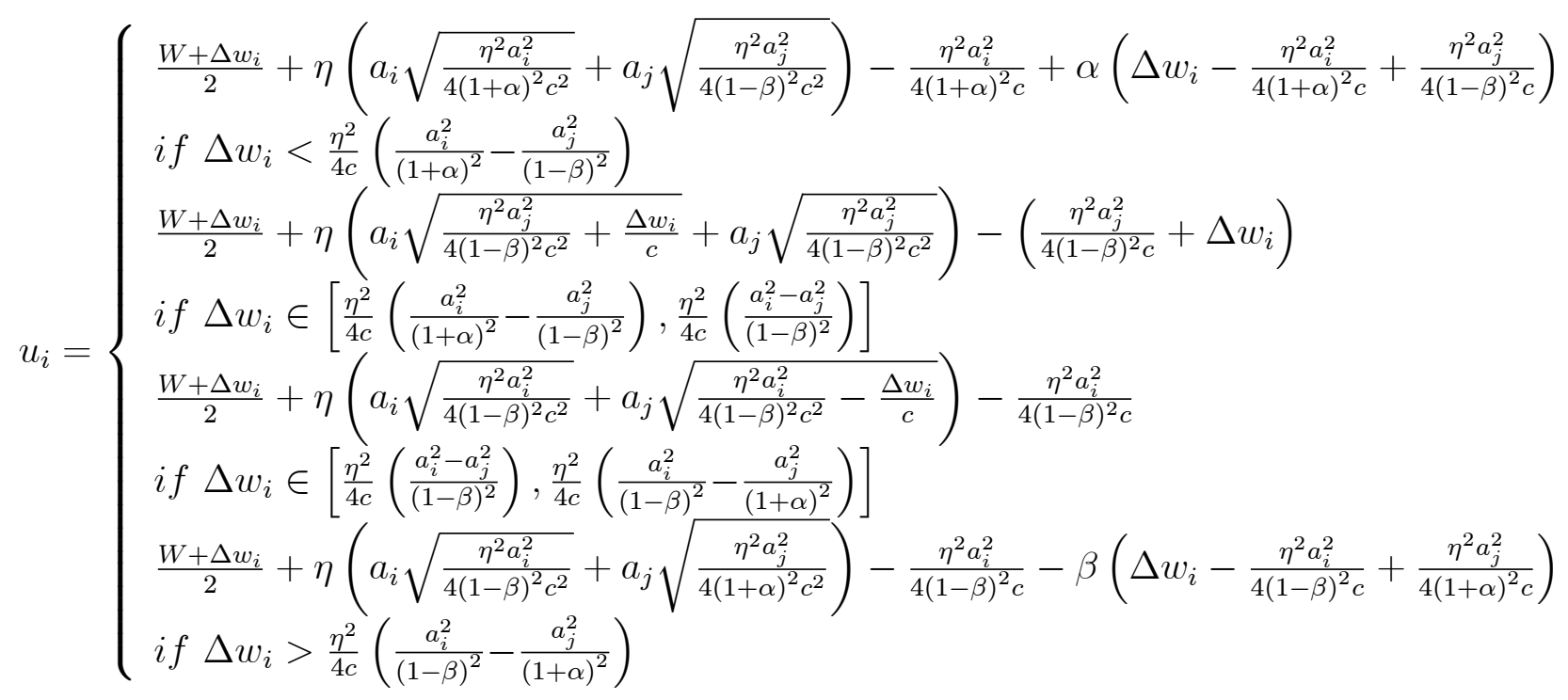


The first derivative of this function is

$$
\frac{\partial u_{i}}{\partial \Delta w_{i}}= \begin{cases}\frac{1}{2}+\alpha & \text { if } \Delta w_{i}<\frac{\eta^{2}}{4 c}\left(\frac{a_{i}^{2}}{(1+\alpha)^{2}}-\frac{a_{j}^{2}}{(1-\beta)^{2}}\right) \\ -\frac{1}{2}+\frac{\eta \cdot a_{i}}{2 c \sqrt{\frac{\eta^{2} a_{j}^{2}}{4(1-\beta)^{2} c^{2}}+\frac{\Delta w_{i}}{c}}} & \text { if } \Delta w_{i} \in\left[\frac{\eta^{2}}{4 c}\left(\frac{a_{i}^{2}}{(1+\alpha)^{2}}-\frac{a_{j}^{2}}{(1-\beta)^{2}}\right), \frac{\eta^{2}}{4 c}\left(\frac{a_{i}^{2}-a_{j}^{2}}{(1-\beta)^{2}}\right)\right] \\ \frac{1 \cdot a_{j}}{2 c \sqrt{\frac{\eta^{2} a_{i}^{2}}{4(1-\beta)^{2} c^{2}}-\frac{\Delta w_{i}}{c}}} & \text { if } \Delta w_{i} \in\left[\frac{\eta^{2}}{4 c}\left(\frac{a_{i}^{2}-a_{j}^{2}}{(1-\beta)^{2}}\right), \frac{\eta^{2}}{4 c}\left(\frac{a_{i}^{2}}{(1-\beta)^{2}}-\frac{a_{j}^{2}}{(1+\alpha)^{2}}\right)\right] \\ \frac{1}{2}-\beta & \text { if } \Delta w_{i}>\frac{\eta^{2}}{4 c}\left(\frac{a_{i}^{2}}{(1-\beta)^{2}}-\frac{a_{j}^{2}}{(1+\alpha)^{2}}\right)\end{cases}
$$

Note that the slope in the second interval is strictly positive if

$$
\begin{aligned}
-\frac{1}{2}+\frac{\eta \cdot a_{i}}{2 c \sqrt{\frac{\eta^{2} a_{j}^{2}}{4(1-\beta)^{2} c^{2}}+\frac{\Delta w_{i}}{c}}} & >0 \Leftrightarrow \\
\frac{\eta^{2}}{4 c}\left(4 a_{i}^{2}-\frac{a_{j}^{2}}{(1-\beta)^{2}}\right) & >\Delta w_{i}
\end{aligned}
$$

which is always true for any $\Delta w_{i} \in\left[\frac{\eta^{2}}{4 c}\left(\frac{a_{i}^{2}}{(1+\alpha)^{2}}-\frac{a_{j}^{2}}{(1-\beta)^{2}}\right), \frac{\eta^{2}}{4 c}\left(\frac{a_{i}^{2}-a_{j}^{2}}{(1-\beta)^{2}}\right)[\right.$ and $\beta \leq \frac{1}{2}$. Furthermore, it is always positive at $\Delta w_{i}=\frac{\eta^{2}}{4 c}\left(\frac{a_{i}^{2}-a_{j}^{2}}{(1-\beta)^{2}}\right)$ for any $\beta \leq \frac{1}{2}$ and equal to zero if and only if $\beta=\frac{1}{2}$.

Similarly, the slope in third interval is strictly negative if

$$
\begin{aligned}
\frac{1}{2}+\eta \cdot & a_{j} \frac{-\frac{1}{c}}{2 \sqrt{\frac{\eta^{2} a_{i}^{2}}{4(1-\beta)^{2} c^{2}}-\frac{\Delta w_{i}}{c}}}<0 \Leftrightarrow \\
\frac{\eta^{2}}{4 c}\left(\frac{a_{i}^{2}}{(1-\beta)^{2}}-4 a_{j}^{2}\right) & <\Delta w_{i}
\end{aligned}
$$

which is always true as well for any $\left.\left.\Delta w_{i} \in\right] \frac{\eta^{2}}{4 c}\left(\frac{a_{i}^{2}-a_{j}^{2}}{(1-\beta)^{2}}\right), \frac{\eta^{2}}{4 c}\left(\frac{a_{i}^{2}}{(1-\beta)^{2}}-\frac{a_{j}^{2}}{(1+\alpha)^{2}}\right)\right]$ and $\beta \leq \frac{1}{2}$. Furthermore, it is always negative at $\Delta w_{i}=\frac{\eta^{2}}{4 c}\left(\frac{a_{i}^{2}-a_{j}^{2}}{(1-\beta)^{2}}\right)$ for any $\beta \leq \frac{1}{2}$ and equal to zero if and only if $\beta=\frac{1}{2}$. 


\section{Proof of Corollary 2:}

The utility of agent $j$ at $\Delta w_{i}=0$ is always smaller as compared to $\Delta w_{i}=\frac{\eta^{2}}{4 c}\left(\frac{a_{i}^{2}-a_{j}^{2}}{(1-\beta)^{2}}\right)$ if agent $j$ 's utility function is increasing at $\Delta w_{i}=0$ which is the case when

$$
0>\frac{\eta^{2}}{4 c}\left(\frac{a_{i}^{2}}{(1+\alpha)^{2}}-\frac{a_{j}^{2}}{(1-\beta)^{2}}\right) \Leftrightarrow \frac{a_{j}}{a_{i}}>\frac{1-\beta}{1+\alpha} .
$$

If this is not the case we have to compare the utility of the less able agent $j$ at the local maximum of both agents' utility function

$$
\frac{W}{2}-\frac{\eta^{2}\left(a_{i}^{2}+a_{j}^{2}\right)}{8(1-\beta)^{2} c}+\frac{\eta^{2}\left(a_{i}^{2}+a_{j}^{2}\right)}{2(1-\beta) c}
$$

with her utility at $\Delta w_{i}=0$, which for $\frac{a_{j}}{a_{i}}<\frac{1-\beta}{1+\alpha}$ is given by

$$
\frac{W}{2}+\frac{\eta^{2} a_{j}^{2}}{2(1-\beta) c}+\frac{\eta^{2} a_{i}^{2}}{2(1+\alpha) c}-\frac{\eta^{2} a_{j}^{2}}{4(1-\beta)^{2} c}+\beta\left(\frac{\eta^{2} a_{j}^{2}}{4(1-\beta)^{2} c}-\frac{\eta^{2} a_{i}^{2}}{4(1+\alpha)^{2} c}\right) .
$$

Hence, agent $j$ is better off with an unequal income when

$$
\frac{a_{j}^{2}}{a_{i}^{2}}>\frac{1}{(1-2 \beta)}\left(\frac{4(1-\beta)^{2}}{(1+\alpha)}+1-4(1-\beta)-\frac{2 \beta(1-\beta)^{2}}{(1+\alpha)^{2}}\right)
$$

Note that if $\left(\frac{4(1-\beta)^{2}}{(1+\alpha)}+1-4(1-\beta)-\frac{2 \beta(1-\beta)^{2}}{(1+\alpha)^{2}}\right)<0$ this holds for all values of $a_{j}$. As $4 \beta-3<0$ this condition is equivalent to

$$
\left((1+\alpha)-\frac{2(1-\beta)^{2}}{(3-4 \beta)}\right)^{2}>\frac{2(1-\beta)^{2}}{(3-4 \beta)^{2}}\left(6 \beta^{2}-7 \beta+2\right)
$$

Note that $6 \beta^{2}-7 \beta+2>0$ as this function is $=0$ at $\beta=\frac{1}{2}$ and decreasing 
for $0<\beta<\frac{1}{2}$. Rearranging the equation gives

$$
\alpha>\frac{1-\beta}{3-4 \beta} \sqrt{2\left(6 \beta^{2}-7 \beta+2\right)}+\frac{2(1-\beta)^{2}}{(3-4 \beta)}-1
$$

which proves the first claim. If, however, $\left(\frac{4(1-\beta)^{2}}{(1+\alpha)}+1-4(1-\beta)-\frac{2 \beta(1-\beta)^{2}}{(1+\alpha)^{2}}\right)>$ 0 , the condition is equivalent to

$$
\frac{a_{j}}{a_{i}}>\sqrt{\frac{1}{(1-2 \beta)}\left(\frac{4(1-\beta)^{2}}{(1+\alpha)}+1-4(1-\beta)-\frac{2 \beta(1-\beta)^{2}}{(1+\alpha)^{2}}\right)}
$$

which establishes the second claim. 